\title{
Development of Intermediate-Grade (Mantle Cell) and Low-Grade (Small Lymphocytic and Marginal Zone) Human Non-Hodgkin's Lymphomas Xenotransplanted in Severe Combined Immunodeficiency Mouse Models
}

\author{
Jerry Bryant, Lan Pham, Linda Yoshimura, Archito Tamayo, Nelson Ordonez, and \\ Richard J. Ford \\ Department of Molecular Pathology (JB, LP, LY, AT, RJF), and the Department of Pathology (NO), The University \\ of Texas, M.D. Anderson Cancer Center, Houston, Texas
}

\begin{abstract}
SUMMARY: We have used severe combined immunodeficiency (SCID) (c.b.-17, ICR/SCID) mice to develop xenotransplantation (XT) models for human intermediate-and-low-grade non-Hodgkin's lymphomas (NHL). In the past, SCID mice have provided a variety of useful XT models for human hematopoietic neoplasms that primarily involve the acute leukemias and some nonhematopoietic tumors, but only rare reports exist on use of the SCID mouse model in the study of primary tumor cells from $\mathrm{NHL}$. Intermediate-grade and low-grade NHL are the most common lymphomas seen in adults. There is no effective therapy for those types of $\mathrm{NHL}$, and they have not been established in an animal model to date. The lack of an animal model has hampered studies that can evaluate the disease process in vivo as well as the definition of therapeutic parameters involved in treatment. We report in this study that primary patient samples of $\mathrm{NHL}$ ( intermediate grade and low grade) have been successfully established in SCID mice after XT. NHL include intermediate-grade (mantle cell lymphoma) and low-grade (eg, small lymphocytic lymphoma/chronic lymphocytic lymphoma and marginal zone lymphoma) forms. Studies have been directed toward creating appropriate conditions for the optimal grafting of these NHL in SCID mice so that the disease process in humans could be accurately simulated. These studies indicate that development of XT-human lymphoma cells in SCID mice appear to be linked to their biologic and/or clinical behavior, transplanted lymphoma cell number, and age, as well as to the natural killer cell status of the SCID mouse recipients. Evidence has also shown that NHL cells can exhibit homing or trafficking patterns in SCID recipients that resemble those observed in patients with gastrointestinal lymphomatous involvement (particularly that of mantle cell lymphoma). Our studies also indicate that artefactual influences, such as the outgrowth of Epstein-Barr virus-associated lymphoblastoid lesions, are rare occurrences in the human NHL/SCID models that we have established. (Lab Invest 2000, 80:557-573).
\end{abstract}

\begin{abstract}
Non-Hodgkin's lymphomas (NHL) are a heteroge1 neous group of human lymphoid tumors of primarily B-cell lineage (NHL-B) that appear to correspond to various stages in normal B-cell ontogeny. B-cell lymphomas vary considerably in their clinical behavior, as described in the older Working Formulation (WF) (Anonymous, 1982). These lymphomas range from low-grade (indolent) to high-grade (aggressive) histotypes that correspond in part to various cellular proliferation indices (flow cytometry, cell cycle analysis, tumor growth fraction, labeling index, etc.) of the lymphoma cells. One important group of NHL-B is the small B-cell lymphocytic lymphomas, which include the low-grade small lymphocytic lymphomas
\end{abstract}

Received December 7, 1999.

Supported by grants CA16672, CA65412, CA62594, and CA67540 from the National Cancer Institute.

Address reprint requests to: Dr. R. J. Ford, Department of Molecular Pathology, The University of Texas M.D. Anderson Cancer Center, 1515 Holcombe Boulevard, Houston, Texas 77030, Tel. No. (713) 792-3121, Fax No. (713) 794-4672. E-mail address: rford@notes.mdacc.tmc.edu
(SLL/CLL), the marginal zone lymphomas (MZL), and the intermediate-grade mantle cell lymphomas (MCL). These NHL-B histotypes are included in the recent Revised European-American Lymphoma Classification (REAL) classification (Harris et al, 1994) that provides more recent molecular, immunologic, and cytogenetic correlates than does the older WF. Although some molecular genetic data (eg, bcl-1 expression in $\mathrm{t}(11: 14)$ containing $\mathrm{MCL}$ ) have been obtained from specific examples of the small-cell NHL-B, little information exists regarding basic biologic aspects of the pathophysiologic characteristics of these tumors. Better biologic definitions of these common NHL-B are important because of significant differences in patients' response to therapy as well as prognosis in cases of the relatively indolent SLL/CLL and MZL histotypes versus the more aggressive MCL, which are usually refractory to current therapy. The MZL include several histopathologic cell types and tissue patterns (including the extranodal mucosaassociated lymphoid tissue lymphomas) or MALT with monocytoid B cells, plasmacytoid cells, etc. (Isaacson et al, 1999a; 1999b). To better understand these 
NHL-B and because of the limited scope of experimental oncologic studies that can be performed in patients, there is a genuine need for developing preclinical in vivo models in experimental animals that can accurately simulate human malignant diseases. Preclinical animal models can then be used for experimental studies on the pathogenesis of NHL-B, as well as for new approaches to patient therapy. Current approaches include the development of a unique transgenic (or gene-inactivated "knockout") animal or xenotransplantation (XT) of human neoplastic tissue into an immune-deficient animal. The transgenic animal should be able to recapitulate at least elements of the disease process, and xenotransplantation should enable the study of in vivo characteristics of human tumor cells in a mammalian model. A current model of the latter type is the severe combined immunodeficiency (SCID) (c.b. 17 ICR/SCID) mouse (Bosma et al, 1983; Mosier et al, 1988). SCID mice, first described by Bosma and coworkers (Bosma et al, 1983), have no functional B-lymphocytes or T-lymphocytes because of a congenital abnormality in the VDJ recombinase enzyme system. This enzyme system is involved in antigen receptor (immunoglobulin [lg] and $\mathrm{T}$-cell receptor) gene rearrangement that is effectively blocked in both T-cell and B-cell maturation in SCID mice (Hesse et al, 1987; Lieber et al, 1988 Malynn et al, 1988). SCID mice have been used in many laboratories as recipients for the $\mathrm{XT}$ of normal and neoplastic human tissues and cell types (Bosma and Carrol, 1991; Custer et al, 1985; Duchosal et al, 1992; Lehmann et al, 1995; Martino et al, 1993; Sandhu et al, 1994; Waller et al, 1991). Studies on hematologic malignancies in SCID mice have primarily involved various forms of the human myeloid leukemias (Beran et al, 1993; Beran et al, 1994; Cesano et al, 1992; Chelstrom et al, 1994; Namikawa et al, 1993; Sawyers et al, 1992. However, we have shown (Ford et al, 1996) that a repertoire of primary patient samples of both NHL (Burkitt's lymphoma, immunoblastic lymphoma, or diffuse large-cell lymphoma) and Hodgkin's disease can be established in SCID recipients. In this study we report the successful xenotransplantation of the lowgrade and intermediate-grade small lymphocytic NHL-B in SCID mice. This model can be used to create preclinical SCID/NHL models of the human disease process. (Ford et al, 1998).

\section{Results}

General Characteristics of Intermediate-Grade and Low-Grade Human Malignant Lymphomas Xenotransplanted into SCID Mice

The major goal in establishing a preclinical animal model of low-grade and intermediate grade NHL-B was to determine study parameters for successful xenotransplantation. These parameters included the evaluation of the grafting of primary human lymphoma cells from a large, diverse, and unselected group of human malignant lymphoma patients after XT into immune-deficient SCID mouse recipients. Most initial XT studies in SCID mice in which conditions regarding the animals' age, lymphoma cell numbers transplanted, and duration of time to grafting were not established were unsuccessful. However, after these parameters had been established, later studies resulted in the development of a reproducible SCID lymphoma model for several important histotypes of NHL-B.

During the course of these studies, more than 100 SCID mice underwent xenotransplantation with freshly obtained NHL (MCL, MZL, and SLL/CLL) cells. The overall success rate for lymphoma grafted in this group of SCID mice was approximately $84 \%$. In Table 1 , our experience in establishing successful human lymphoma xenotransplants in SCID mice, including overall XT success rate, average time to grafting, and posttransplantation interval, is summarized for $\mathrm{NHL}$ histotypes. In this table, we show that indolent NHL usually required longer periods of time (13 to 22 weeks) for grafting than the time intervals indicated in earlier studies (3 to 6 weeks) for the more aggressive forms of NHL, including diffuse large-cell lymphoma, Burkitt's lymphoma, and immunoblastic lymphoma. After the time interval for the tumor grafting had elapsed, SCID mice showing visual or palpable signs of tumor growth were killed. Gross necropsy photography and microscopic histopathologic examination of paraffin sections (hematoxylin-eosin [H\&E] stain) from involved murine tissue were used to demonstrate lymphoid tumor cell infiltration.

Tumor was detected in the animals' lymphoid organs (spleen, lymph nodes) and in parenchymal organs (liver, kidneys), as well as extranodally in the form

Table 1. Human Non-Hodgkin's Lymphoma Transplanted into Severe Combined Immunodeficiency Mice (Revised European-American Lymphoma Classification)

\begin{tabular}{|c|c|c|c|c|c|}
\hline \multicolumn{6}{|l|}{$\begin{array}{l}\text { Lymphoma } \\
\text { type(s) }\end{array}$} \\
\hline \multirow{2}{*}{$\begin{array}{l}\text { Non-Hodgkin's } \\
\text { B-cell } \\
\text { neoplasmas }\end{array}$} & \multirow{2}{*}{$\begin{array}{c}\text { No. SCIDs } \\
\text { xenotransplanted }\end{array}$} & \multirow{2}{*}{$\begin{array}{l}\text { Success } \\
\text { rate }(\%)\end{array}$} & \multirow{2}{*}{$\begin{array}{l}\text { No. of SCIDs } \\
\text { grafted }\end{array}$} & \multicolumn{2}{|c|}{$\begin{array}{c}\text { Average* time of } \\
\text { development (weeks) }\end{array}$} \\
\hline & & & & Average & Range \\
\hline MCL & 30 & 83 & 25 & 13 & $(12-20)$ \\
\hline SLL & 47 & 81 & 38 & 22 & $(20-28)$ \\
\hline MZL & 8 & 88 & 7 & 13 & $(12-20)$ \\
\hline
\end{tabular}

No., Number; SCID, severe combined immunodeficiency; MCL, mantle cell lymphoma; SLL, small lymphocytic lymphoma; MZL, marginal zone lymphoma. 
of peritoneal or retroperitoneal masses. The sites of involvement often replicated the pattern observed in the patients' original tumor presentation. Monoclonality in the various xenotransplanted NHL lymphoid tumor type(s) was determined by polymerase chain reaction $(\mathrm{PCR})$ from the primary patient tumor and from the grafted tumor tissue obtained from the SCID mice. The NHL-B histotypes (MCL, SLL/CLL, or MZL) grafted in SCID mice showed similar morphologic characteristics and the relatively consistent growth patterns of NHL tumor type(s) in the SCID mouse organs and extranodal tissues.

Subsequent analyses of cell surface markers with panels of monoclonal antibodies directed against cell surface antigens that define the histotypes of the indolent lymphomas studied were conducted. The results showed that no significant phenotypic changes in the patients' original tumor cell surface immunophenotypes occurred after xenotransplantation of tumors in the SCID model. Details of the experimental determination of parameters for the establishment of the NHL histotypes in the SCID models are described below. Because earlier preliminary XT studies that involved significant numbers of human NHL-B cells in SCID mice ( 20 to $50 \times 10^{6} /$ mouse) had failed to show evidence of grafting after up to 1 year in vivo, we decided to ascertain whether the lack of success could be due to insufficient numbers of tumor cells transplanted. To test this hypothesis, we used patients with higher lymphoma cell yields from their biopsy specimens or, in some cases, those with leukemic forms of MCL, so that more tumor cells could be obtained. The age of the SCID recipients was also considered as a possible variable to be evaluated experimentally to determine whether younger animals are more receptive to $\mathrm{XT}$.

\section{Effect of SCID Recipient Age on the Grafting of MCL in SCID Mice}

For these experiments, two groups of SCID mice were studied. The first group consisted of twenty-four 6-week-old SCID mice; 12 were pretreated with 25\% antiasialo GM (AGM), and 12 were untreated. The second group consisted of twenty-four 3-week-old mice, of which 12 had been pretreated with AGM and 12 were untreated. MCL cells from a single patient were injected intravenously and intraperitoneally in combination at the same time. Preliminary studies indicated that the combination route of administration was superior to either route alone. In these experiments, the primary human MCL cells were successfully grafted in all 12 of the AGM pretreated SCID mice that were 3 weeks of age at the time of XT (Fig 1 A to F). Tumors appeared in SCID mice 4 to 6 months after transplantation; the minimum cell number was $\geq 250 \times 10^{6}$ malignant cells per animal (Table 2). However, the primary MCL cells were not successfully grafted in any of the SCID mice that were 6 weeks of age at XT (Table 2). The 6- week-old group and 10 of 12 of the 3-week-old group that were untreated remained free of gross or microscopic tumor for more than 9 months. Grafted tumor cells were recovered from solid tumor masses or infiltrated organs from the 3-week-old group of SCID mice, and those cells were subsequently passed on to multiple SCID recipients for further studies on these lymphomas. Corroboration that authentic MCL cells in addition to human B-cell antigens (SIg, CD5, CD20, etc.) had been grafted in these SCID mice was obtained by the demonstration that cyclin D1 (or Prad 1) protein (a biologic marker of MCL cells) was expressed in the grafted tumor cells. Immunohistochemistry studies that used antibodies to the cyclin D1 protein were performed on MCL tumor tissue and on the original patient biopsy sample. Both diagnostic specimens from the patient (not shown) and the SCID xenograft exhibited strong, tumorspecific staining that signified overexpression of cyclin D1 (Fig 1c).

\section{Possible Role of Murine Natural Killer Cells (NK) in NHL Xenotransplantation in SCID Mice}

Preliminary studies using standard Cr51-release from YAC (a murine lymphoma cell line) sensitive to NK cell lysis cell NK assays were undertaken to evaluate the functional NK capacity of 3- and 6-week-old SCID mice, because the differences in transplantation receptivity in those age groups could be due to NK responses. As shown in Fig. 2, the NK activity is much higher than $3 \%$ in both the 6-week-old SCID mice and the control mice. However, in the 3-week-old SCID mice, the NK activity is nonexistent. As shown previously, increasing the number of tumor cells transplanted in the 3-week-old SCID recipients increased the rate of grafting, which is shown in Figures $3 \mathrm{~A}$ and $B$. However, increasing tumor cell number alone in 6-week-old SCID mice did not increase the rate of grafting in either the intermediate-grade or the lowgrade NHL-B, as shown on Table 3 . In contrast, in 3-week-old SCID mice, an increase in tumor cell numbers increased the rate of grafting of both intermediate-grade and low-grade NHL-B tumors. These data suggest that age and tumor cell number contribute to the success of grafting of these types of NHL-B cells in this SCID mouse model. In Figure 2, the 3-week-old mice had virtually no NK in their spleen, while the NK activity was significant in 6-week-old SCID mice when compared with that in control (nonimmune deficient) adult mice.

\section{Effect of Lymphoma Cell Number on NHL Grafting in the SCID Mouse}

Preliminary studies indicated that low-grade and intermediate-grade $\mathrm{NHL}$ (MCL and SLL) require a significantly higher number of malignant cells for successful XT ( $\times 10$ to 50$)$ than do aggressive NHL-B (data not shown). In most of these NHL-B, our studies showed that increasing the number of lymphoma cells at XT decreases the length of time required for tumor manifestation. To test the hypotheses that xenogeneic grafting of NHL-B cells in the SCID model is in part cell-number dependent and that a graft threshold 

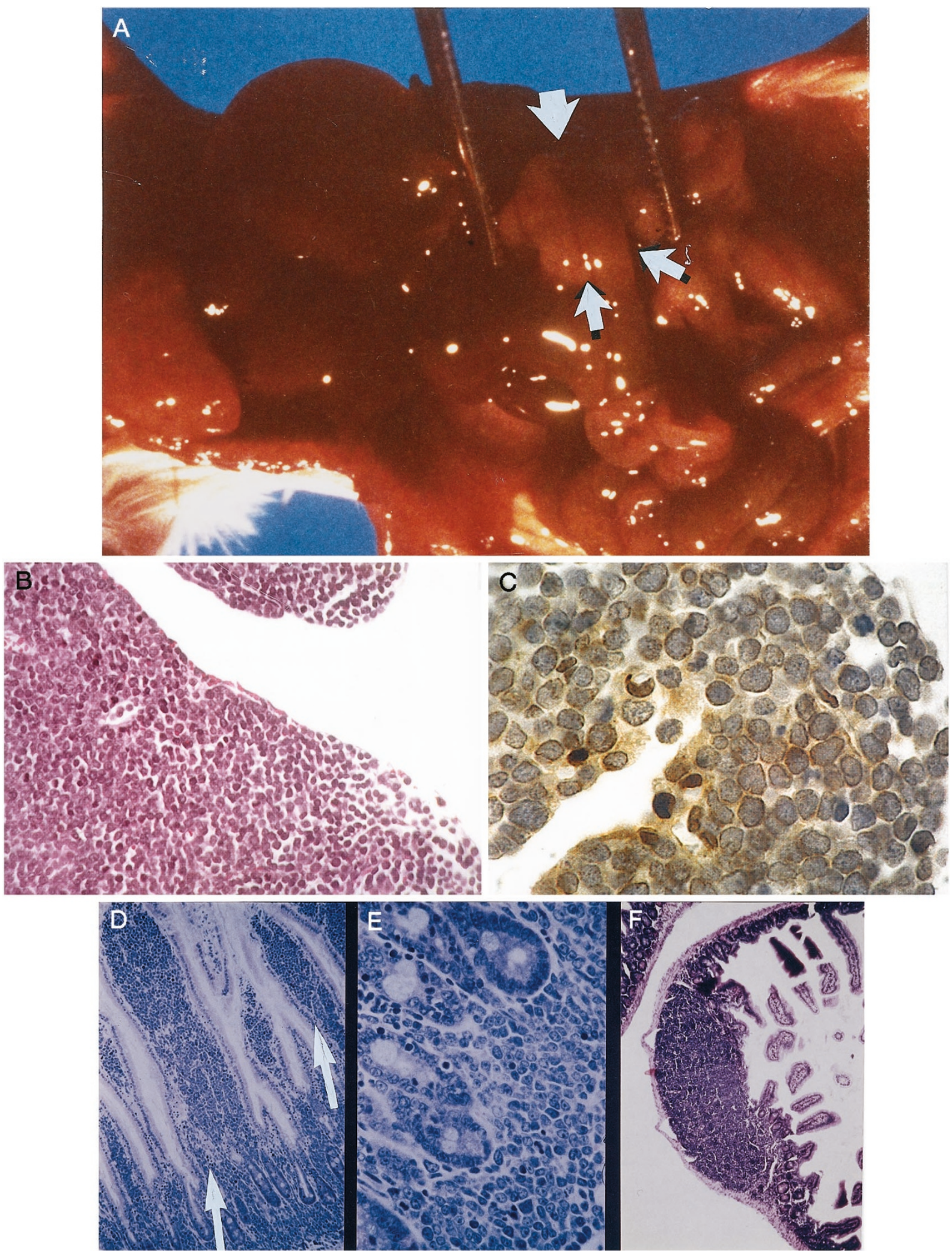

\section{Figure 1.}

Mantle cell lymphoma (MCL). A, Gross photograph of a severe combined immunodeficiency (SCID) mouse that underwent xenotransplantation with freshly obtained MCL cells from a patient in the leukemic phase of the disease. At necropsy, infiltration of MCL cells was found in the abdominal organs; note the propensity for localization at various locations in the gastrointestinal tract, including the wall of the small intestine shown here. B, Microscopic section showing infiltration of the mesentery of the gastrointestinal tract with typical MCL cells (hematoxylin \& eosin [H\&E], $125 \times$ ). C, Section from the same lesion showing characteristic immunocytochemical staining for cyclin D1. Cells from the patient showed the $t(11: 14)$ bcl-1 translocation and displayed the CD5+, 10-, 23-, 43+ immunophenotype on flow cytometry analysis $(\mathrm{H \& E}, 420 \times)$. D, MCL xenotransplanted from another patient. Microscopic section showing MCL intestinal involvement. The lymphoma cells infiltrating the lamina propria (arrow) of the intestinal villi produce a multiple lymphomatous polyposis-like appearance. E, A higher power of (D) showing 
Table 2. Mantle Cell Lymphoma Grafts in 6-Week-Old Severe Combined Immunodeficiency Mice Versus 3-Week-0Id Severe Combined Immunodeficiency Mice After Pretreatment with Anti-asialo GM or Controla

\begin{tabular}{ccccc}
\hline \multicolumn{5}{c}{ Mantle cell lymphoma } \\
\hline No. SCID & Age (weeks) & $\begin{array}{c}10^{6} \text { Cells } \\
\text { per Animal }\end{array}$ & Pretreatment & Tumor \\
\hline $12 / 12$ & 6 & 250 & - & Negative \\
$12 / 12$ & 6 & 250 & + & Negative \\
$2 / 12$ & 3 & 250 & - & Positive \\
$10 / 12$ & 3 & 250 & - & Negative \\
$12 / 12$ & 3 & 250 & + & Positive \\
\hline
\end{tabular}

a Sham injection with saline.

SCID, severe combined immunodeficiency.

\section{NK Activities in 3 and 6 weeks old SCID Mice Splenocytes}

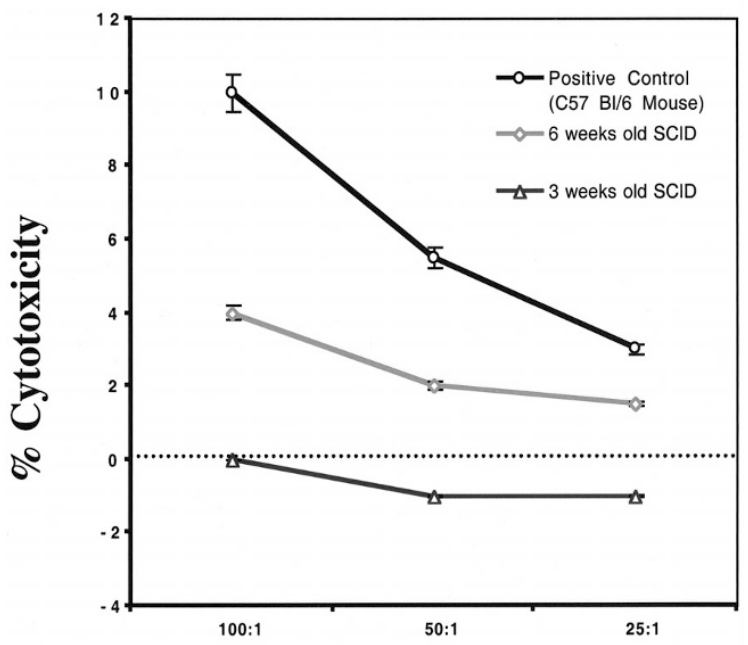

Effector: Target Ratio

Figure 2.

Cytotoxic reactivity at various effector:target-cell ratios of splenocytes from

exists, below which grafting does not occur. We performed in vivo experiments with MCL and SLL/ CLL. As shown in Figure 3A, we transplanted a representative MCL; the figure illustrates that a doseresponse relationship exists between the number of cells used in xenotransplantation and the time interval for tumor appearance. There also appears to be a minimum tumor cell dose threshold $\left(50 \times 10^{6}\right)$ required for successful XT. Injecting fewer than $50 \times 10^{6}$ or $450 \times 10^{6} \mathrm{MCL}$ and SLL cell numbers, respectively, produced no evidence of tumor establishment in vivo in SCID mice, even after 48 weeks and 28 weeks, respectively (Figs. $3 A$ and $B$ ).

A protocol similar to that of the MCL study was used to study low-grade SLL/CLL; however, 48 mice per

\section{A Mantle Tumor Growth Data}

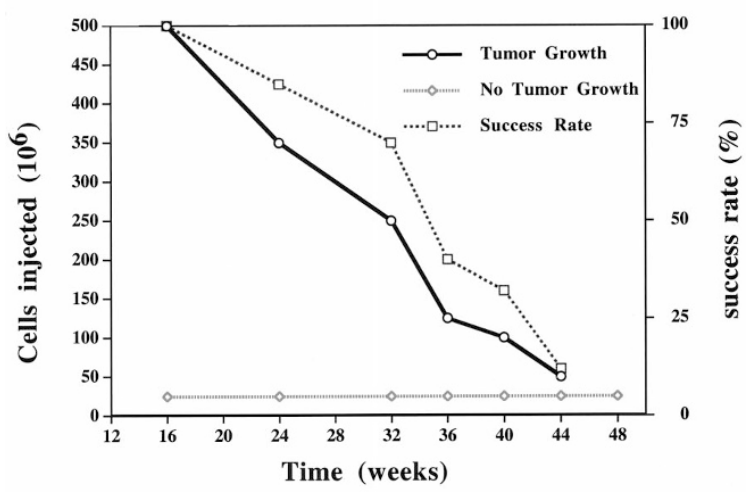

B SLL Tumor Growth Data

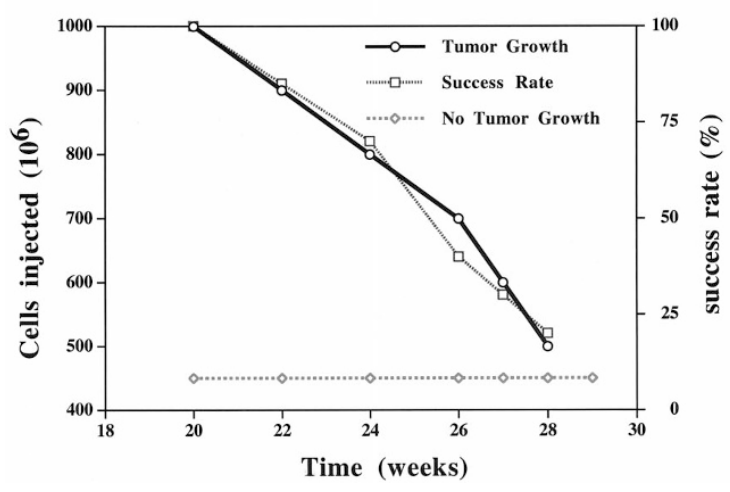

Figure 3.

A, Tumor cell dose response vs time (in weeks) for tumor appearance in SCID mice in which freshly obtained MCL cells were transplanted. B, Tumor cell dose response vs time (in weeks) for tumor appearance in SCID mice in which freshly obtained small lymphocytic lymphoma (SLL) cells were transplanted.

group were used. Of twenty-four 6-week-old mice, 12 were pretreated with AGM, and 12 were sham-treated with only saline. Of twenty-four 3-week-old mice, 12 were pretreated with AGM, and 12 were treated with vehicle saline only. All SCID mice were injected with a minimum of $2.5 \times 10^{8} \mathrm{MCL}$ cells and $5.0 \times 10^{8}$

infiltration of the submucosa and intestinal glands by MCL cells $(430 \times)$. F, SCID/MCL obtained from a third patient with MCL. MCL intestinal infiltration from a SCID mouse showing a more nodular pattern of infiltration of reactive B-cell follicles and involvement of the submucosal and mucosal regions. C.B-57 B1/6 mice pretreated 24 hours with $100 \mathrm{mg}$ of poly I:C (positive control) and C.B-17 SCID mice 3 weeks old (blue) and 6 weeks old (red) against yeast artificial chromosome-1 tissue culture target cells. Percentage cytotoxicity with a standard deviation. MW, Molecular weight marker; SLL, small lymphocytic lymphoma. 
Table 3. Grafts of Small Lymphocytic Lymphoma in 6-Week-Old Severe Combined Immunodeficiency Mice Versus 3-Week-Old Severe Combined Immunodeficiency Mice After Pretreatment with Anti-asialo GM or Control ${ }^{\mathrm{a}}$

\begin{tabular}{ccccc}
\hline \multicolumn{5}{c}{ SLL/CLL lymphoma } \\
\cline { 2 - 5 } No. SCID & Age (weeks) & $\times 10^{6}$ Cells & Pretreatment & Tumor \\
\hline $12 / 12$ & 6 & 500 & + & Negative \\
$12 / 12$ & 6 & 500 & - & Negative \\
$2 / 12$ & 3 & 500 & - & Positive \\
$12 / 12$ & 3 & 500 & + & Positive \\
\hline
\end{tabular}

a Sham injection with saline.

Note: Experiment was repeated twice. Total of 24 animals in each group (Experiment: No. of animals in the experimental group/total number of animals.)

SLL/CLL, Small lymphocytic lymphoma; SCID, severe combined immunodeficiency.

SLL/CLL cells. Results of these studies indicated that large numbers of MCL cells and SLL/CLL cells are also required for a successful graft (Tables 2 and 3 ). None of the twenty-four 6-week-old SCID mice injected demonstrated a successful tumor graft, whether or not they had been pretreated with AGM. However, in the 3-week-old SCID mice, $83 \%$ of the MCL tumor grafts and $81 \%$ of SLL tumor grafts were successful (Tables 1-3). All grafts were successful in the 3-week-old SCID mice pretreated with AGM, while in the 3-week-old AGM-untreated SCID mice, only 2 of 12 demonstrated successful grafts (Tables 2 and 3 ).

\section{Specific Characteristics of Low-Grade and Intermediate-Grade Lymphomas in SCID Mice}

Mantle Cell Lymphoma (MCL). MCL is an intermediate-grade lymphoma (according to the WF) that is usually quite aggressive and is associated with poor survival, primarily as a result of its disseminated presentation and the failure of current therapy. In patients, MCL can be either nodular or diffuse and can assume a "mantle-zone" appearance. A more aggressive "blastic" form of MCL that can resemble diffuse large-cell lymphoma also occurs. In SCID mice that have undergone XT with MCL, we have observed the disseminated growth of MCL cells throughout the peritoneal cavity as well as infiltrates in the spleen and liver and occasionally in the lungs. These cases show the general immunophenotype of MCL (CD5, $20+; 10,23-)$ on flow cytofluorogram (FCM) analysis and demonstrate cyclin D1+ on immunohistochemical analysis (Fig. 1C). In SCID mice that underwent XT from MCL patients who exhibited trafficking of lymphoma cells to the gastrointestinal tract, we observed infiltration into the lamina propria and intestinal glands in a manner that simulated MLP (multiple lymphomatous polyposis) in the human donor (Fig. 1D).

Marginal Zone Lymphoma (MZL). Another small-cell indolent NHL-B is the marginal zone (or cell) lymphoma (MZL), which often occurs in the spleen (splenic marginal zone lymphoma, provisional category, REAL classification) but is also observed in nodal or extranodal lymphoid tissue (nodal or extranodal [including mucosa-associated lymphoid tissue]; MALT lymphoma, provisional category, REAL classification). Morphologically, MZL is characteristically heterogeneous and exhibits small atypical lymphocytes, which are small centrocyte-like cells resembling follicular center cells (but often with more cytoplasm) that are similar to monocytoid B lymphocytes and often include plasmacytoid B cells. In Figure 4A, a necropsy photo shows massive $(20 \times)$ splenomegaly (arrow) and extensive peritoneal involvement with MZL lymphoma. In this case, microscopic infiltration with typical MZL cells was also observed in a paraspinal nerve ganglion (Fig. 4B) These MZL cells resembled the original patient biopsy material consisting of atypical small, round, and occasionally cleaved lymphoid cells. H\&E staining and flow cytometry studies on MZL cases were consistent with the phenotypic analysis of the original patient biopsy. A representative case is shown in Table 4D.

Low-Grade Non-Hodgkin's Lymphoma (NHL): Small Lymphocytic Lymphoma/Chronic Lymphocytic Leukemia (SLL/CLL). Small lymphocytic lymphoma (SLL) can be the tissue counterpart of chronic lymphocytic leukemia (CLL), or it can arise as a small-cell indolent NHL-B. In the SCID/SLL/CLL mice, the lymphoma grew slowly and often took 9 months or longer to develop. Figures $5 \mathrm{~A}$ and $\mathrm{B}$ include a necropsy photo from a SCID/SLL/CLL mouse that shows an abdominal mass involving visceral organs, as well as a microscopic view of a section from that abdominal mass (H\&E stain). On microscopic examination, the lymphoma cells are characteristic small lymphocytes with round-to-oval nuclei containing condensed chromatin and small inconspicuous nucleoli. The tumor cells in the SCID/SLL lesions appear as sheets of small lymphoid cells that are similar to or slightly larger than normal lymphocytes. In typical lesions, lighter staining areas are often observed. Those areas appear to correspond to slightly larger cells with greater amounts of cytoplasm and more prominent nucleoli (fig. 5c) that could represent pseudofollicular proliferation centers.

\section{Epstein-Barr Virus Analysis}

In our study, we were able to rule out Epstein-Barr virus (EBV)-mediated lymphoproliferative disease, which could have been an artefact of our procedures. To help discriminate transformed EBV-associated lymphoblastoid tumor cells, analysis with a standard PCR method for EBV was routinely performed on lymphoid tumor cells from SCID mice. EBV-specific 

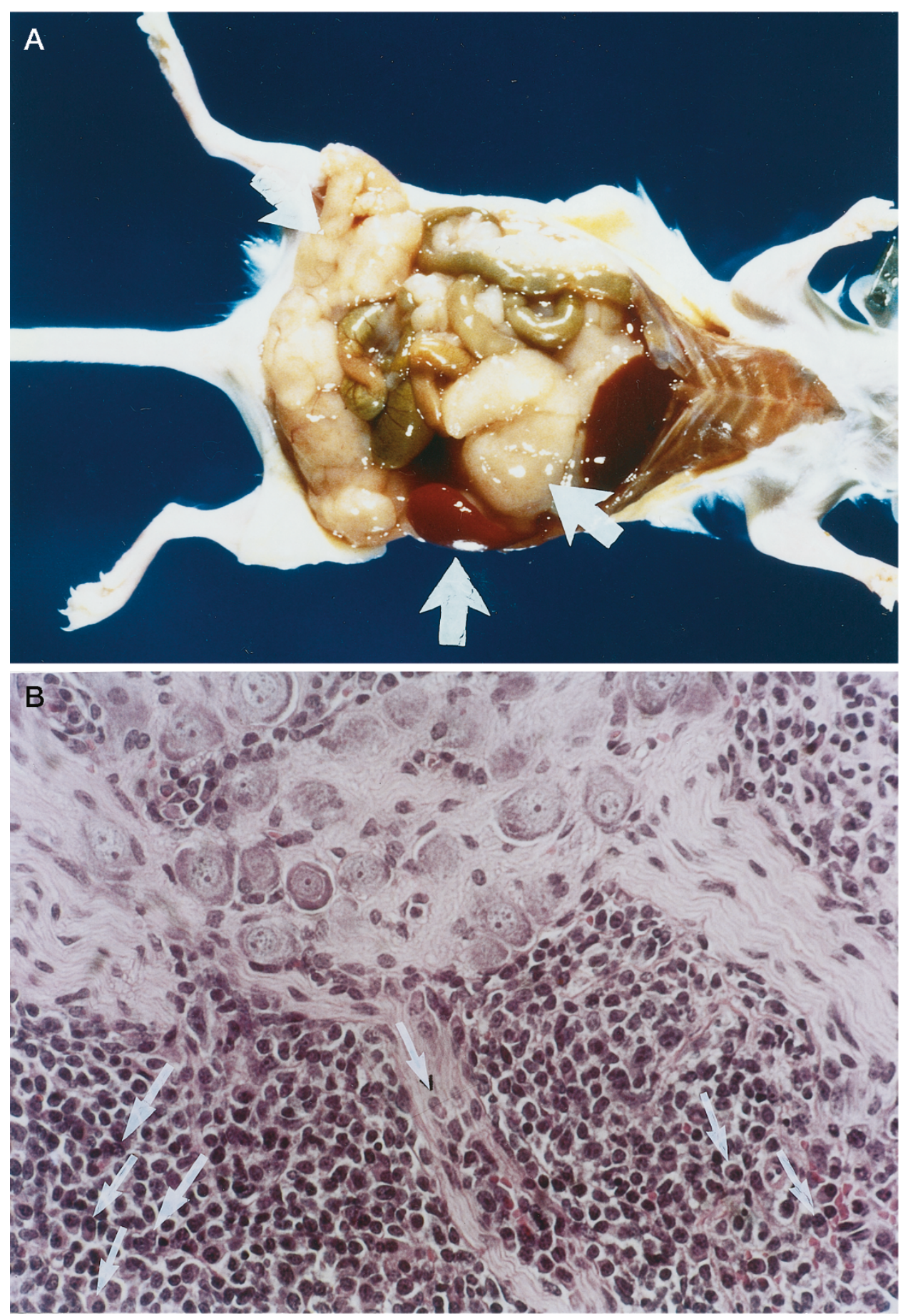

\section{Figure 4.}

Marginal zone B-cell lymphoma. A, Necropsy photo of a low-grade MZL in an SCID mouse recipient 12 weeks after transplantation of MZL cells from the patient's spleen. Extensive infiltration of abdominal viscera was observed in addition to splenomegaly (arrow). B, Involvement of a large paraspinal nerve ganglion and a large nerve root (arrow) by MZL cells $(H \& E, 250 \times$ ). Immunophenotype of lymphoma cells removed from the tumor showed IgM+, CD5, 10,23- consistent with the patient's original biopsy diagnosis of marginal zone lymphoma (MZL).

primers were used to analyze representative human lymphoid tumors from SCID mice that had undergone XT when EBV-mediated lymphoproliferative disease was possible after histopathologic examination and immunophenotyping (eg, large-cell lymphomas, intermediate grade, etc.). In our entire experience with the xenotransplantation of NHL in SCID mice, only two of the non-Burkitt's lymphoma lymphoid tumor samples assayed in our series were found to be EBV-positive by that method. Both of those tumors were morphologically intermediate-large lymphoid cells. The neoplasms were oligoclonal and probably represented EBV-associated lymphoblastoid nonmalignant outgrowths (transformants) of residual normal B cells 

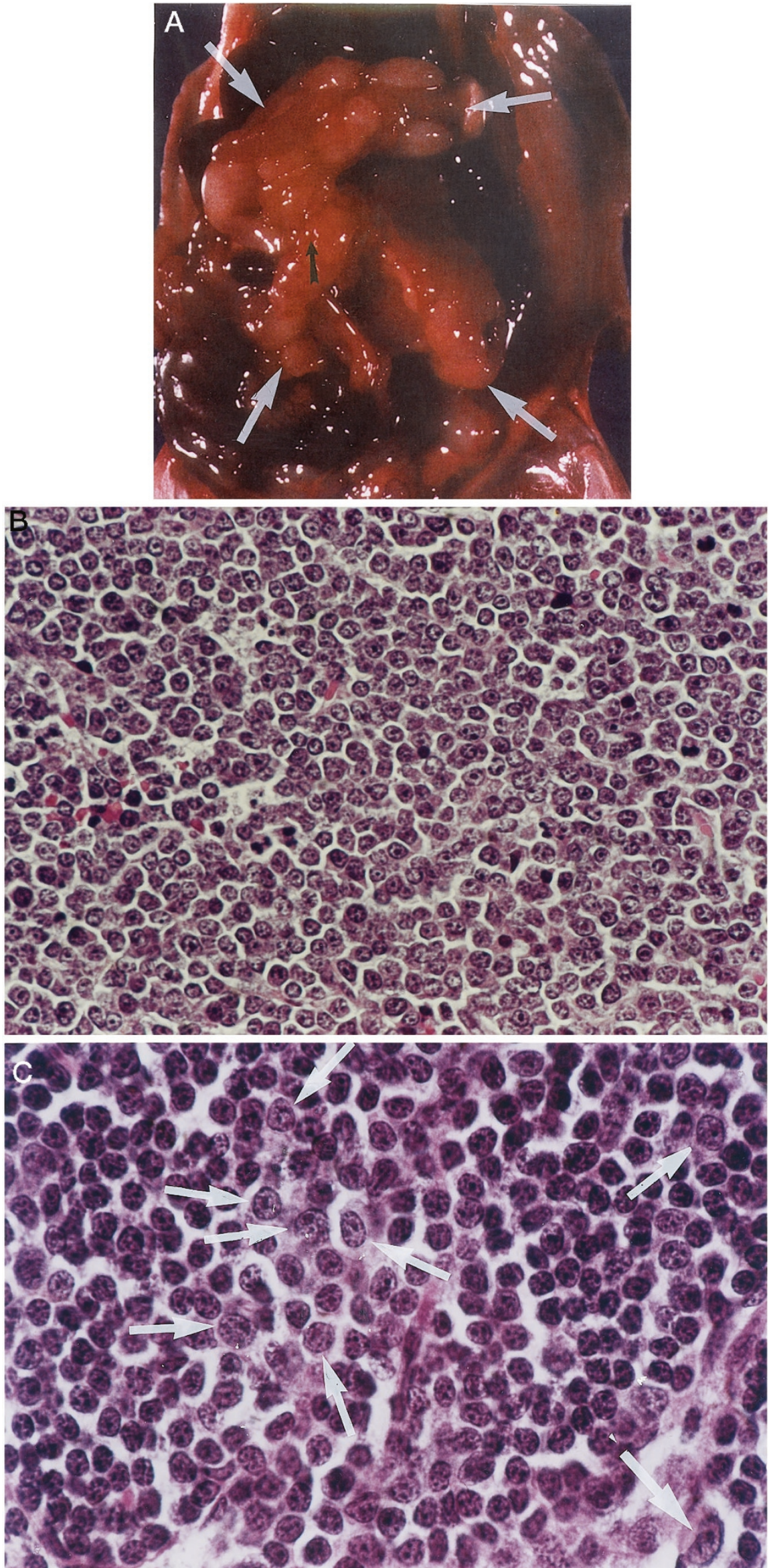
Table 4. Human Versus Mouse Immunologic Markers on Severe Combined Immunodeficiency/Lymphoma Tumor

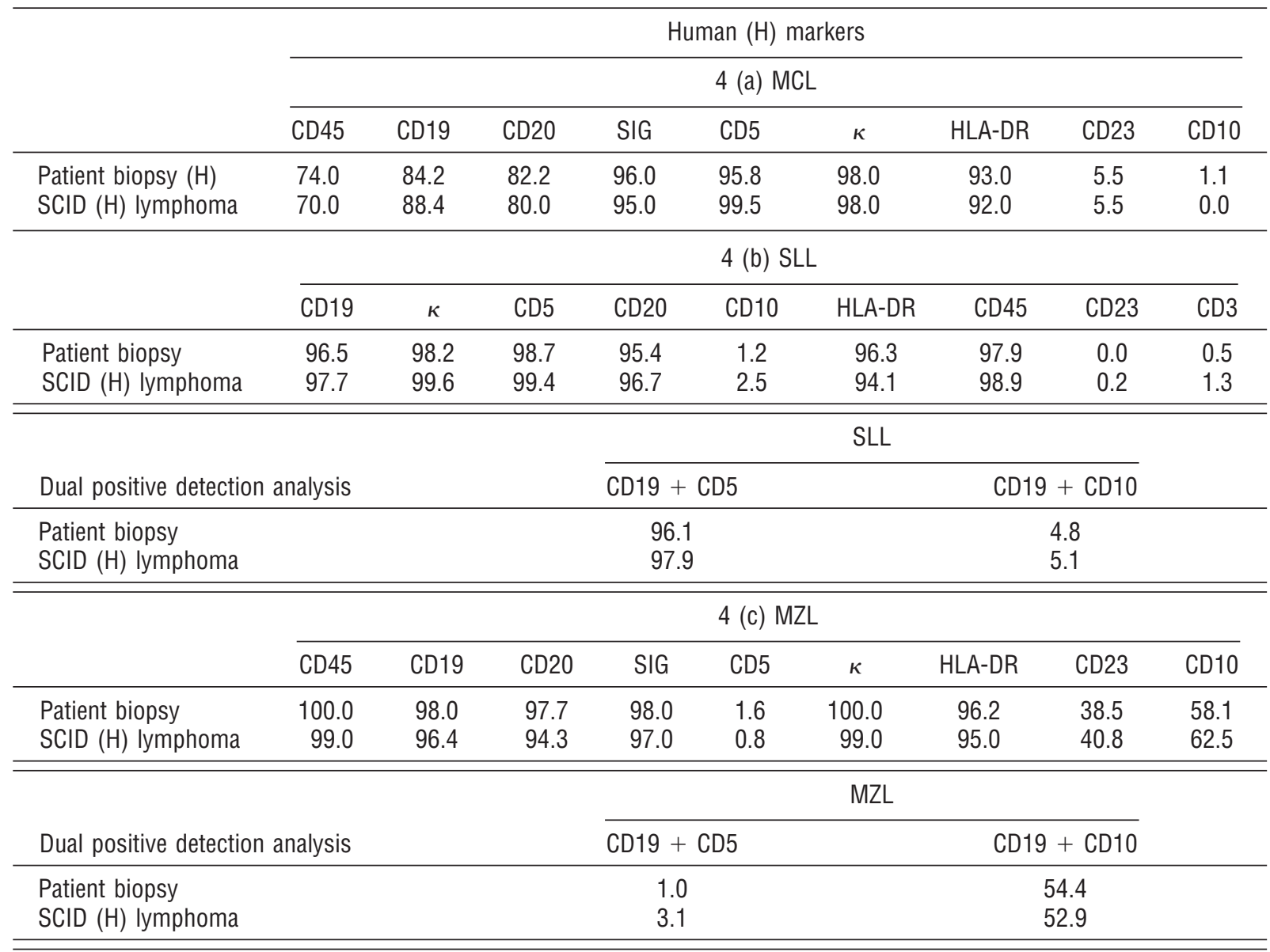

\begin{tabular}{|c|c|c|c|c|c|c|c|}
\hline & \multicolumn{7}{|c|}{ Mouse markers } \\
\hline & \multicolumn{7}{|c|}{4 (d) Control } \\
\hline & CD45R & $\mathrm{CD} 4$ & CD8 & SIG & Thy1.2 & $\kappa$ & LY1.2 \\
\hline Patient biopsy & 0.2 & 0.0 & 0.0 & 2.8 & 0.0 & 0.0 & 0.0 \\
\hline SCID $(H)$ lymphoma & 0.5 & 0.0 & 0.0 & 2.5 & 0.0 & 0.0 & 0.0 \\
\hline
\end{tabular}

Comparison of FACS analyses performed on tumor cells obtained from an SCID mouse that underwent xenotransplantation and the original biopsy from a patient with non-Hodgkin's B-cell lymphoma. (a) SCID-H-MCL; (b) SCID-H-SLL, SCID-H-SLL-dual positive; (c) H-MZL, SCID-H MZL-dual positive; and (d) mouse-specific monoclonal antibodies. In this study both human and mouse antigens were used to detect human cell surface antigens on the lymphoma cells.

MCL, Mantle cell lymphoma; SCID, severe combined immunodeficiency; SLL, small lymphocytic lymphoma; MZL, marginal zone lymphoma.

from the original specimen grafted in the SCID mice, although monoclonal, EBV, EBV+ NHL were not observed in our series. Figure 6 shows a representative example of several SCID mice with SLL or MCL grafts that were tested for EBV by PCR. In addition to the molecular parameters, morphologically EBV + lymphoblastoid cells are usually larger and resemble diffuse large cell lymphomas (NHL-B) rather than MCL, SLL, or MZL, which are usually small lymphocytic NHL-B.

\section{Clonal Analysis of Intermediate-Grade (Mantle Cell Lymphoma) and Low-Grade (Small Lymphocytic Lymphoma and Marginal Zone Lymphoma) NHL Xenotransplanted in SCID Mice}

To validate the relationship of the lymphoma in the SCID mouse to that in patients with NHL-B, the molecular findings of $\mathrm{NHL}$ samples from the original patient sample and the xenotransplanted tumor from SCID mice were analyzed and compared. Represen-

\section{Figure 5}

Small lymphocytic lymphoma (SLL). A, Necropsy photo of an SCID mouse that had been injected intraperitoneally and intravenously with SLL cells 24 weeks before being killed. An abdominal mass with extensive involvement of visceral organs can be seen. B, Microscopic view of a section from the abdominal lymphomatous mass shown above. A diffuse monomorphous pattern of small, round lymphoid cells resembling SLL/CLL cells was observed. C, Microscopic view shows a lighter zone area (arrows) with unique binucleolated cells with large amounts of cytoplasm in each cell $(\mathrm{H} \& \mathrm{E}, 450 \times)$. The lymphoma cells also exhibit a monotypic light chain $(\kappa)$ staining in addition to CD5 and other B-cell markers. 

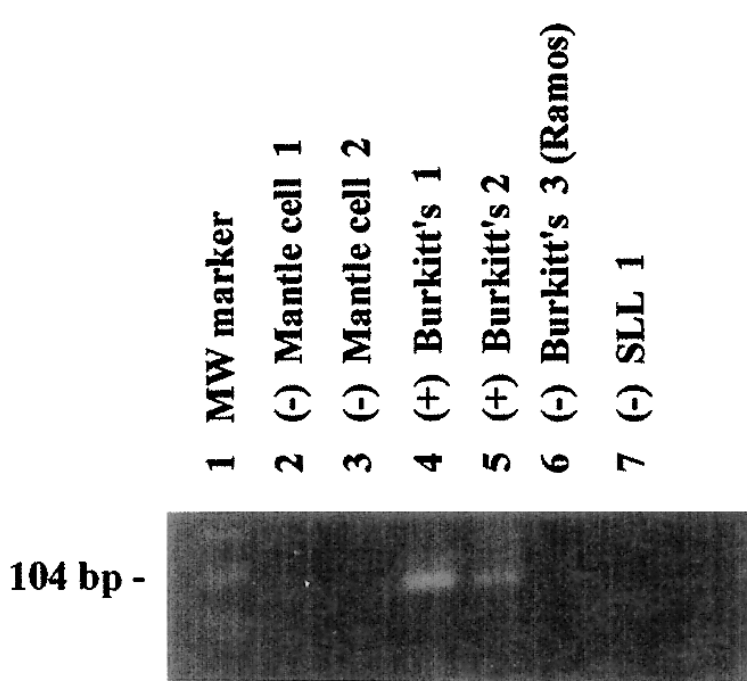

Figure 6 .

SCID xenotransplanted lymphomas from patients with B-cell non-Hodgkin's lymphoma were tested for the Epstein-Barr virus (EBV) genome by means of polymerase chain reaction (PCR) with primers described in the Materials and Methods section.

tative samples included three samples from patients and three samples from the SCID mice that had undergone $\mathrm{XT}$ with one intermediate-grade $\mathrm{MCL}$ and two low-grade SLL/CLL and MZL lymphomas (Fig. 7). The PCR products of $\sim 300 \mathrm{bp}$ in size were obtained in all three patient and SCID mouse samples as shown in Figure 7. In the intermediate-grade and low-grade lymphomas, there was agreement between the flow cytometric analysis and the PCR as to the presence of clonality. Human immunoglobulin $\mathrm{H}$ gene rearrangement has been detected in approximately $90 \%$ of the engrafted tumor cells from SCID mice that have been studied.

\section{Flow Cytometric Analysis of Human and SCID Xenotransplanted Intermediate-Grade and Low-Grade NHL}

To further characterize lymphoma cells removed from XT tumors, single-cell suspensions were immunophenotyped by flow cytometry. Analysis with the described panel of monoclonal antibodies indicated that the phenotypes of the MCL, SLL/CLL, and MZL tumor cells recovered from the SCID mice were concordant with or identical to the original primary patient tumor (Table $4 \mathrm{~A}$ to $\mathrm{C}$ ). These findings further support the concept that intermediate-grade and low-grade NHL that retain $\mathrm{B}$-cell lineage markers and the genotype of the original patient biopsy cells can be xenotransplanted in the SCID model, in addition to aggressive NHL. Figure 8 shows an example of a flow cytofluorogram of an MCL obtained from an SCID mouse 5 months after XT. Note the MCL cell expression of the B-cell antigens, CD5, CD20, and Slg, as well as the $\lambda$ light chain as a marker of monoclonality (Kappa in negative). Figure 9 shows color histograms with scatter plots that representing the SLL cells obtained from a SCID mouse 12 months after XT. The histograms

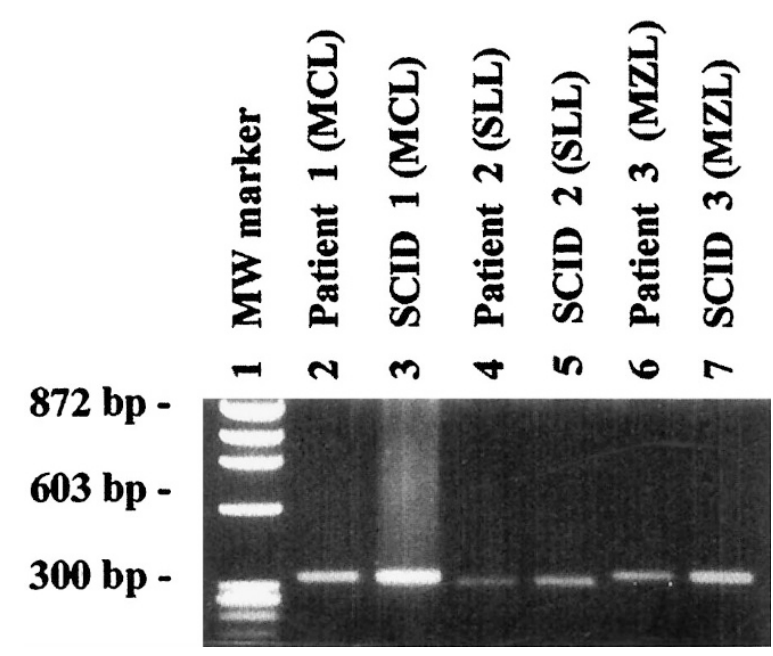

Figure 7.

Clonal IgH gene rearrangements in lymphoma genomic DNA from three representative lymphoma patients with small-cell NHL-B; original biopsies and corresponding xenotransplanted lymphomas from SCID mice are shown. Genomic DNA from lymphoma patient biopsies or from XT of the biopsy cells in SCID mice as amplified by means of PCR with VH3 and JH primers (shown in the Materials and Methods section). MW, Molecular weight marker; MCL, mantle cell lymphoma; SLL, small lymphocytic lymphoma; MZL, marginal zone lymphoma.

detect specific human cell surface markers on the tumor cells that are associated with SLL/CLL (CD5, CD19, CD20, HLA-DR, $\kappa+$ positive; CD3, CD23, CD10-negative). The phenotypic markers for MCL, SLL/CLL, and MZL (Table 4 A to C) were identified and were concordant with the patients' original biopsy, which demonstrates a close correlation between the cell surface antigens on the xenotransplanted lymphoma cells in SCID mice and the original patient biopsy tissue(s). In Figure 10, CD19 and CD5 are positive surface markers on SLL cells in SCID mice, which would be expected in SLL/CLL. Finally, Table 4D confirms that murine cell surface antigens are not expressed on the xenotransplanted lymphoma cells, which signifies that the xenotransplanted lymphoma in SCID mice represents a tumor derived from the patient's xenotransplanted biopsy cells and not from endogenous murine lymphoid cells.

\section{Discussion}

Recently, better immunodeficient rodent models such as SCID mice have provided an improved second generation (when compared with the earlier nude mice) of preclinical in vivo models for XT studies of a variety of human tumors and the characterization of human neoplastic cell growth in vivo (Duchosal et al, 1992; Fidler, 1986; Flavell et al, 1996). In the past 3 years, we have been able to xenotransplant a wide range of primary NHL and Hodgkin's disease tumor cells into SCID mouse recipients (Ford et al, 1996; Ford et al, 1998). This model may provide experimental approaches to basic and clinical questions about neoplastic cell growth regulation, as well as information about the intrinsic sensitivity of xenotransplanting 
A

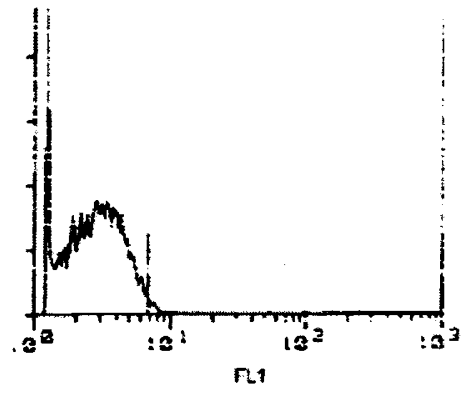

Control isotype
B

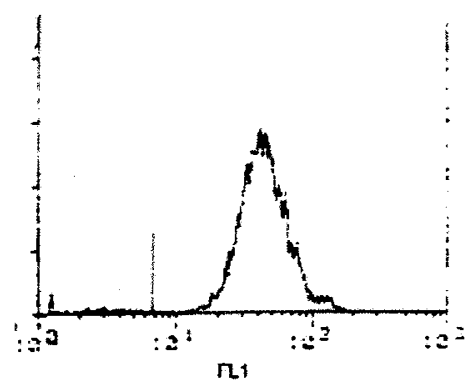

anti-Human $\mathrm{CD} 45$

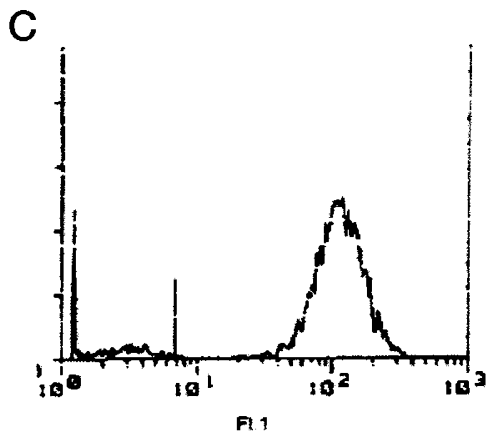

anti-Human CD20

F

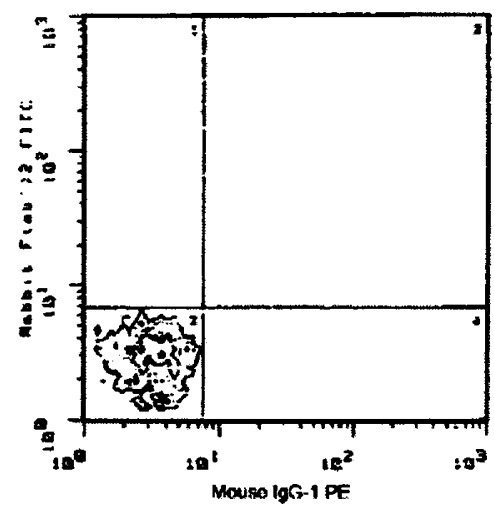

Control isotype

Rabbit F(ab')2 FITCMouse lgG-1 PE
D

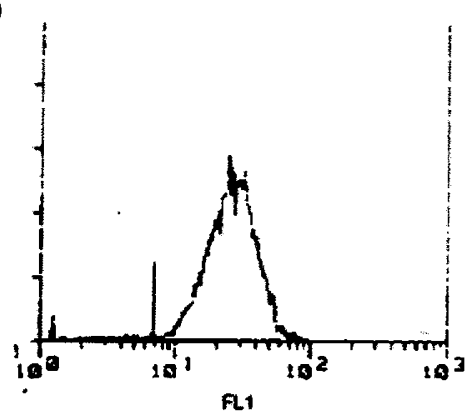

anti-Human CD5

G

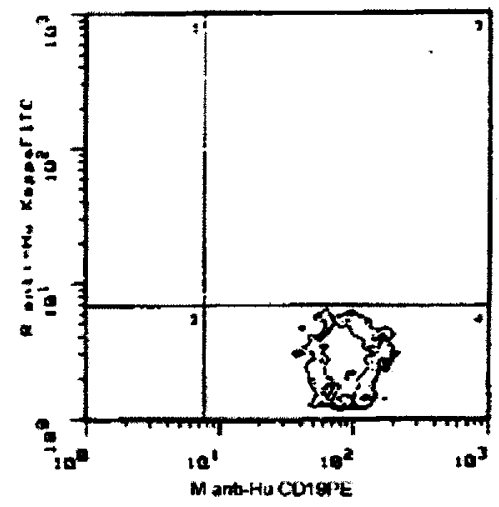

Rabbit amitHu Kappa FITC Mouse anti-Hu CD19 PE
E

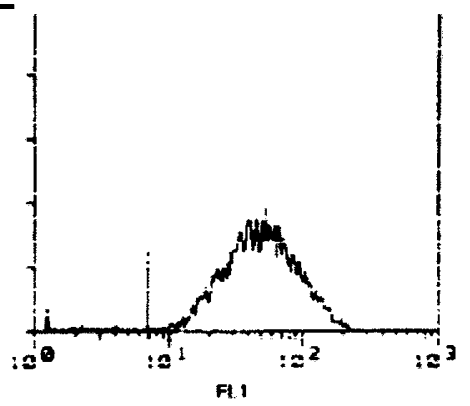

anti-Human Sig

$\mathrm{H}$

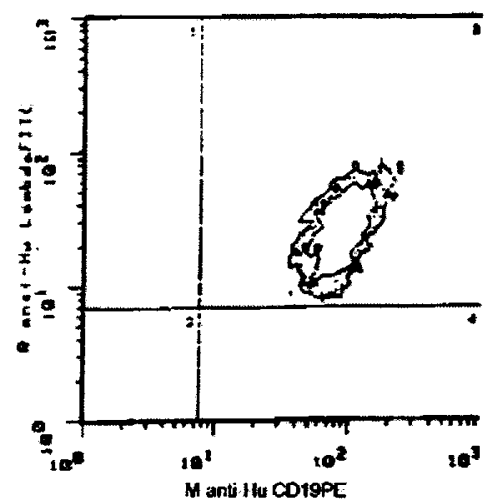

Rabbin anti Hu Lambda FITC Mouse antittu CD19 PE

\section{Figure 8.}

Flow cytofluorogram showing expression of CD19, CD20, CD5, CD45, Slg, and kappa and lambda antigens on an SCID mouse tumor graft from a fresh patient sample of MCL. A, Single fluorescence histogram for mAb mouse control isotype-FITC. B, An antihuman CD45-FITC. C, CD20-FITC. D, CD5-FITC. E, SIg surface immunoglobulin $F\left(a b^{\prime}\right)^{2}$. F, Dual color analysis with $m A b$ rabbit $F\left(a b^{\prime}\right)^{2}$ FITC/mouse lgG-1 used as control isotype PE. G, Kappa-FITC/CD19-PE, (H) Lambda-CD19-PE. Flow cytofluorogram of the SCID mouse tumor was compared with the immunophenotype of the original biopsy from the patient (data not shown). All scales are logarithmic.

human ML cells to new potential therapeutic agents (Kamel-Reid and Dick, 1988).

Although we have been able to xenotransplant a wide spectrum of aggressive ML, the small lymphocytic (indolent) lymphomas, which are an important group of $\mathrm{NHL}$, became our focus because of their unknown pathogenesis and the inability to successfully cultivate or propagate these lymphomas in vitro.
Among the various histotypes of non-Hodgkin's lymphomas recognized by the current REAL (Harris et al, 1994) and future World Health Organization classifications, the small-cell low-grade (indolent) B-cell NHL are of particular interest and importance because of their common occurrence and poor response to therapy. Some small-cell indolent NHL-B that were not recognized by the earlier WF have only recently been 


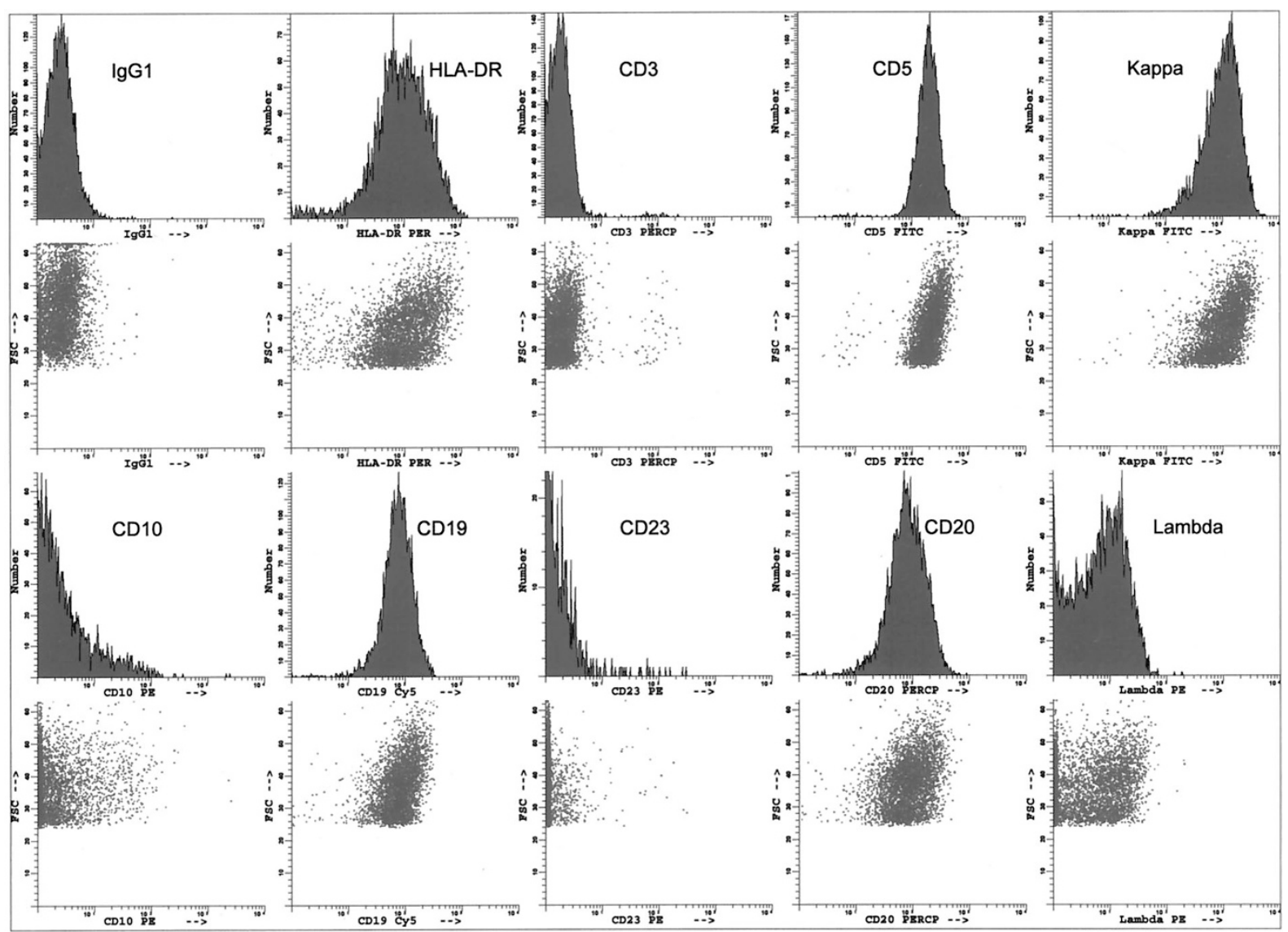

\section{Figure 9.}

Color flow cytometric analysis of SCID SLL non-Hodgkin's B-cell lymphoma. Histograms and scatter plots of tumor cells that had been labeled with a panel of monoclonal antibodies. Quadrants were set according to isotype-matched negative control staining.

defined; for example, the nodal marginal zone lymphomas that are cytologically similar to the extranodal mucosa-associated lymphoid tissue MALT lymphomas. While the small cell NHL-B often appear quite similar histopathologically, there have been few biologic studies on these lymphomas that could provide important insights into neoplastic cellular growth potential and other pathophysiologic characteristics. Such studies should provide valuable approaches for future therapeutic endeavors.

The results described in this study demonstrate that several histotypes of primary low-grade and intermediate-grade lymphomas (marginal zone, small lymphocytic, and mantle cell) NHL-B cells can be successfully xenotransplanted into SCID mouse recipients, but only under optimal experimental conditions. Success in achieving XT with human lymphoma cells obtained directly from biopsied tissues appears to depend primarily on several important experimental parameters that have been delineated in our studies. These parameters include the lymphoma histotype, the age of the recipient SCID mouse, the number of xenotransplanted tumor cells, the time interval to grafting, and the NK presence in the SCID mouse (Pham et al, unpublished data, 1999). Although there is some individual variability within the various histotypes of $\mathrm{NHL}$ cases that we have reported in this study, our experience has shown that the low-grade and intermediate-grade small-cell NHL-B require at least 2 to 3 times the number of viable lymphoma cells and at least twice the time interval for grafting in SCID mice than the time intervals required for the aggressive NHL histotypes (diffuse large-cell lymphoma, immunoblastic lymphoma, Burkitt's lymphoma) under similar circumstances in these animals (D'Andrea et al, 1996; Ford et al, 1996; Mosier et al, 1992). The very large numbers of cells required for successful XT in some of the small-cell lymphocytic NHL-B histotypes may at first seem excessive, but our dose-response studies indicate that such numbers are essential for successful grafting. Also, the large numbers of transplanted lymphoma cells required for grafting appeared to cause no immediate or subsequent physical distress, disorientation, or short-term morbidity in the mice after the transplantation procedure.

The major goal of this study was to determine parameters for establishing the xenotransplantation potential and graft rate of primary human lymphoma cells from a large, unselected group of patients with intermediate-grade (mantle cell) or low-grade (smallcell lymphocytic or marginal zone) malignant lymphoma after xenotransplantation into immunedeficient SCID mouse recipients. During the course of these studies, more than 100 SCID mice underwent 


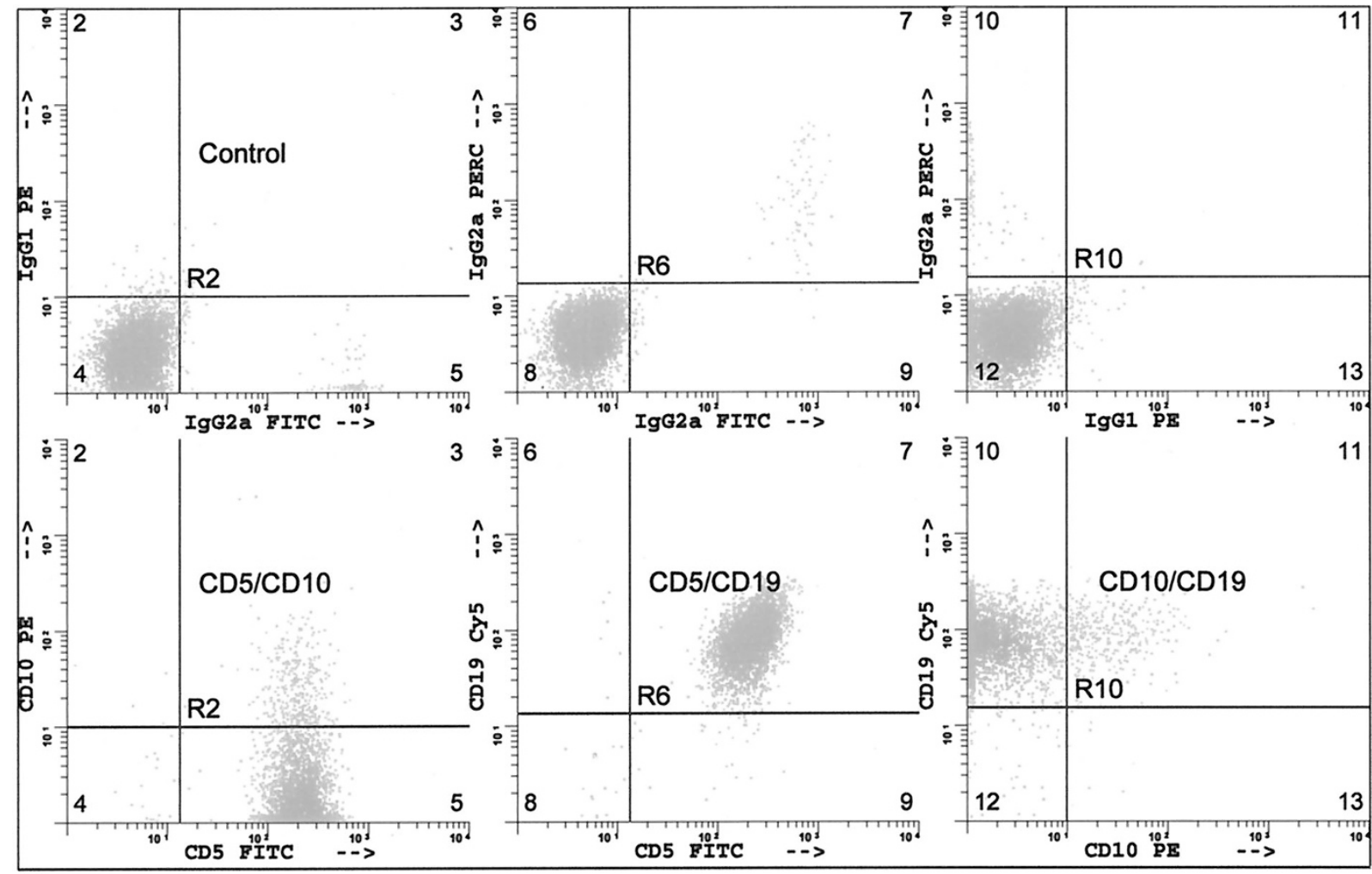

Figure 10.

Color flow cytometric analysis of dual-antigen detection in an SCID-H/SLL tumor.

xenotransplantation with freshly obtained $\mathrm{NHL}$ (intermediate-grade or low-grade) tumor cells from more than 70 patients during a 3-year period. The NK-mediated immunity in the SCID recipients is of interest in these studies. We have shown that NK activity is low in weanling (3-week-old) mice but becomes progressively higher in young and adult (2- to 3-month-old) normal mice. However, NK activity diminishes to an almost nonexistent level by 4 to 5 months of age (Herberman et al, 1975; Herberman et al, 1979; Kiessling et al, 1975; Kiessling and Wigzell, 1979 ; Pham et al, unpublished data, 1999. NK activity is normal in adult (6- to 10-week-old) SCID mice (Dorshkind et al, 1985) but is absent in very young (3to 4-week-old) SCID mice (Lauzon et al, 1986); Pham et al, unpublished data, 1999). In our studies, NK activity in 3-week-old SCID mice is negligible and was further dampened with AGM antisera. Such treatments, by abrogating NK activity during the early postxenotransplantation period, appear to be critical to the later successful outgrowth of the three histotypes of indolent small-cell NHL-B in SCID mice with successful grafts. In addition, our studies seem to indicate that anti-NK treatment at the weanling stage also abrogates the later development of NK activity in the treated SCID mice, but this area needs further study to define the extent of NK dampening under these conditions and its relationship to later tumor development (indolent types) after XT (Pham et al, unpublished data, 1999).
The validity of preclinical animal models like the $\mathrm{SCID/NHL}$ mouse is supported by certain intrinsic tumor markers, such as those for MCL, that characteristically display a nonrandom chromosomal $t(11: 14)$ translocation involving ectopic expression of the Prad 1 (bcl-1; Cyclin D1) gene. Such tumor markers provide another criterion to support the contention that we have successfully established this cell type in our SCID xenotransplantation model. This oncogene is an integral component of the G1 phase of the cell cycle and is overexpressed in MCL (Motokura et al, 1991); Rosenberg et al, 1991 ).

However, the most important result of these studies is the indication that NHL such as intermediate-grade (MCL) or low-grade (SLL or MZL) lymphomas can be successfully xenotransplanted in the SCID model. Because the low-grade (indolent) histotypes of $\mathrm{NHL}$ have not been established in immortalized cell lines and do not spontaneously proliferate significantly in vitro or in response to the known cytokines, the ability to grow and passage such tumor cells in vivo is of particular importance. The marginal zone NHL-B however, represent fewer cases than the SLL or MCL. The shorter time to grafting, which resembles that of the more aggressive intermediate-grade $\mathrm{MCL}$, requires additional study because that histotype is less common in our patient population.

Another important aspect of the SCID/NHL model is that xenotransplanted human lymphoma cells are able to recreate a histopathologic pattern of growth similar 
to that observed in patients (Butcher et al, 1999). In addition, SCID mice express the mucosal addressin cell adhesion molecule (MAdCAM) normally found in the gastrointestinal tract and associated lymphoid tissues. Human lymphoma cells that are able to recognize the various murine tissue-associated adhesion molecules, such as the integrin $\alpha 4 \beta 7$ - MAdCAM-1 addressin paradigm in MCL, may be able to achieve accurate homing that results in the characteristic appearance of multiple lymphomatous polyposis (Drillenberg et al, 1997; Moynihan et al, 1996). SCID/NHL models should therefore allow for further corroboration of MCL gastrointestinal trafficking and other in vivo homing mechanisms (Kroon et al, 1994; Picker et al, 1988). We have also observed similar lymphomaspecific homing patterns similar to those of MCL in the Sézary syndrome/mycosis fungoides (SS/MF) model, in which the SS/MF cells migrate into the SCID skin, invade both the dermis and epidermis, and cause Pautrier's microabscesses (Bryant et al, unpublished data, 1999). Tumor homing and dissemination are particularly important to the pathologic validity of the SCID mouse model (Isaacson et al, 1999) and in establishing the appropriate in vivo microenvironment in the experimental animal for use in future studies assessing the efficacy of potential therapeutic agents.

Finally, the SCID/NHL models can foster studies for studying fundamental questions regarding the biologic nature of these diseases while providing a method for expanding lymphoma cell numbers for a variety of other experimental studies. These studies also suggest that such models can provide experimental approaches to the clinical questions regarding neoplastic cell growth regulation (Bryant et al, unpublished data, 1999), the tissue spread and homing of lymphoma cells with tumor progression, and the intrinsic sensitivity of xenotransplanted human lymphoma cells to potential new therapeutic agents (Sundaresan et al, 1997).

\section{Materials and Methods}

\section{Patient Samples}

Patient tissue samples consisting of biopsied lymph nodes, spleen, body cavity effusions, etc., were obtained immediately after removal under sterile conditions from respective patients. These specimens were obtained through the MDACC Tissue Procurement Core Facility from residual tumor tissue at the time of tissue processing for diagnostic pathologic procedures with informed patient consent according to Institutional Review Board guidelines. The lymphoma cells were then analyzed morphologically on Giemsastained cytospin preparations (Ford et al, 1995) and later on permanent paraffin sections after $\mathrm{H} \& \mathrm{E}$ or immunohistochemical staining and immunophenotyping.

\section{Characterization of Lymphoma Specimens}

Fresh sterile lymphoma tissue from lymph nodes, spleen, etc. was processed within 30 minutes after removal from the patient. Viable lymphoma cell suspension preparations were obtained from specimens by mincing in cold RPMI 1640 medium. The cell suspensions were further purified and selectively enriched for lymphoma cells by standard techniques (Ficoll/Hypaque gradient centrifugation, E-rosetting, magnetic bead cell depletion, etc.) (Ford et al, 1995). Immunophenotyping was performed with a battery of lymphoid lineage-associated monoclonal antibodies (Becton-Dickinson, San Jose, California) by flow cytometry (DeMartini et al, 1988).

\section{Immune-Deficient SCID Mice}

Female c.b.-17-ICR/SCID mice at 3 weeks of age were purchased from Taconic Farms (Germantown, New York). The mice were maintained in the M.D. Anderson Cancer Center SCID Mouse Core Facility, which consists of a standard barrier vivarium, under sterile pathogen-free conditions suitable for immunedeficient rodents. Quality assurance on the integrity of our barrier was monitored by means of sentinel mice that are routinely maintained and killed at defined intervals for testing to identify the potential presence of standard environmental or opportunistic murine pathogens.

\section{Xenotransplantation Procedures}

Lymphoma cell preparations from patient samples were suspended in physiologic saline solution and were injected in varying cell numbers into 3- to 4-week-old SCID mice, either intraperitoneally and/or intravenously through the tail vein. SCID mice were pretreated intraperitoneally with $0.25 \mathrm{ml}$ of (AGM) polyclonal antisera 25\% (v/v) (Wako, Richmond, Virginia) to dampen endogenous NK responses (Dorshkind et al, 1985; Felsher et al, 1990; Pham et al, unpublished data, 1999).

\section{Necropsy for the Assessment of Xenotransplantation}

SCID mice showing signs of tumor involvement (organomegaly, peritoneal mass, limb paralysis, etc.) were killed with appropriate euthanasia procedures. The mice were then subjected to a full necropsy under sterile conditions. Tumor involvement was documented by color photography of gross pathologic lesions in situ. Organs involved with tumor were dissected aseptically, which allowed for tumor cell isolation for further studies involving cell culture and additional serial passage in young SCID mouse recipients. Representative sections of tumor and adjacent tissues were taken and fixed in formalin for routine histopathologic testing on H\&E stained paraffin sections. Other paraffin sections were prepared for immunohistochemistry by means of standard immunoperoxidase techniques (Zukerberg et al, 1995).

\section{Fluorescence-Activated Cell Sorter Analysis}

Cell labeling of tumor cell preparations was performed with viable single-cell suspensions that were analyzed 
by flow cytometry for expression of cell surface antigens (DeMartini et al, 1988; Felsher et al, 1990). Tumor cells were treated with fluorescein-labeled murine monoclonal antibodies (Becton-Dickinson, San Jose, California) for indirect immunofluorescence analysis. Tumor tissue types included peritoneal, abdominal, ovarian, and splenic lymphoid tumors and tumorinfiltrated lymph nodes, as well as lymphoid tumors that had infiltrated the bone marrow and thymus. Mouse phenotypic markers were also assayed to verify the absence of murine antigens on lymphoma cell populations as well as contaminating murine $\mathrm{B}, \mathrm{T}$ lymphocytes, and macrophages (Pharmingen, San Diego, California).

\section{Immunohistochemistry}

For immunoperoxidase staining, a commercial immunohistochemistry system (Oncogene Research Products, Cambridge, Maryland) was used for the localization of antigen (eg, cyclin D1 marker) in paraffin-embedded MCL cells. The paraffin-embedded tissue sections were dewaxed and incubated with unlabeled primary monoclonal antibody. The specifically bound antibody was then visualized by incubation with a biotinylated secondary antibody followed by a preformed avidin-biotinylated horseradish peroxidase macromolecular complex and substrate (Zukerberg, et al, 1995).

\section{NK Cytotoxicity Assay}

The 4-hour ${ }^{51} \mathrm{Cr}$ release assay was performed as follows. Target YAC-1 cells were labeled with $100 \mu \mathrm{Ci}$ of $51 \mathrm{Cr}$ (Amersham, Arlington Heights, Illinois; 2 $\mathrm{mCi} / \mathrm{ml}$ ) for 30 to 45 minutes at $37^{\circ} \mathrm{C}$ in $5 \% \mathrm{CO}_{2}$. These target cells were washed 2 to 3 times and were then counted and resuspended to a desired density. Single-cell suspensions of SCID splenocytes were prepared by grinding the spleen in a tissue-grinding medimachine (Becton Dickinson, San Jose, California). Splenocytes were depleted of red blood cells by agitating them with lysing reagent for 5 to 10 minutes. Cells were washed 2 to 3 times with phosphate buffered saline ( $1 \times$ PBS) (AccuGene, Wallerville, Maryland) or Hank's balance salt solution (HBSS) (Bio-Whittaker, Walkerville, Maryland) and were resuspended in RPMI 1640 medium at certain dilution. Effector and target cells were then incubated at the ratio $(E: T)$ of $100: 1,50: 1$, and $25: 1$ in 96-well round bottom plates in a $37^{\circ} \mathrm{C}-5 \% \mathrm{CO}_{2}$ incubator for 4 hours. ${ }^{51} \mathrm{Cr}$ activity was measured in a gamma counter. The percentage of specific lysis was calculated from the mean of quadruplicate tests. Cytotoxicity was calculated as follows: $100 \times(\mathrm{E}-\mathrm{S} / \mathrm{T}-\mathrm{S})$, where $E$ is the isotope release from experimental wells, $\mathrm{S}$ is the spontaneous release, and $\mathrm{T}$ is the total release (Pham et al, unpublished data, 1999). Data are mean values \pm SE (standard error) for at least two independent experiments with quadruplicate tests.

\section{Detection of IgH Gene Rearrangements}

Identification of a rearranged IgH gene was used as a clonality marker in NHL-B cells. The rearranged $\mathrm{IgH}$ gene was detected by means of the PCR method ( Deane and Norton, 1990). Immunoglobulin heavy chain variable region family usage is independent of tumor cell phenotype in human $\mathrm{B}$ lineage lymphomas. This method uses a panel of seven primers $(\mathrm{VH} 1, \mathrm{VH} 2$, $\mathrm{VH} 3, \mathrm{VH} 4 \mathrm{a}, \mathrm{VH} 4 \mathrm{~b}, \mathrm{VH} 5$, and $\mathrm{VH} 6$ ) selected from six germ-line $\mathrm{VH}$ families and a $\mathrm{JH}$ consensus sequence. The PCR reaction mixture contained $1.25 \mathrm{mmol}$ each of dATP, dTTP, dCTP, dGTP; $67 \mathrm{mmol}$ Tris-HCL $(\mathrm{pH}$ 8.8); $16.6 \mathrm{mmol}(\mathrm{NH} 4) 2 \mathrm{SO}_{4} ; 10 \mathrm{mmol} \mathrm{MgCl}$; $10 \mathrm{mmol}$ $\beta$-ME; $10 \%$ dimethyl sulfoxide; $6.5 \mu$ mole EDTA; 167 $\mu \mathrm{g} / \mathrm{ml}$ bovine serum albumin; $100 \mathrm{ng}$ of each of seven VH primers; $100 \mathrm{ng}$ of the $\mathrm{JH}$ primer; and $1 \mu \mathrm{g}$ of genomic deoxyribonucleic acid. The mixture was then overlaid with mineral oil. After an initial denaturation at $95^{\circ} \mathrm{C}$ for 6 minutes, $0.5 \mathrm{U}$ of Taq polymerase (Promega, Madison, Wisconsin) in $1 \mu \mathrm{L}$ was added to the $29 \mu \mathrm{L}$ PCR mixture. The amplification consisted of 30 cycles of denaturation at $91^{\circ} \mathrm{C}$ for 1 minute, annealing at $62^{\circ} \mathrm{C}$ for 1.5 minutes, and extension at $72^{\circ} \mathrm{C}$ for 1.5 minutes, with a final extension at $72^{\circ} \mathrm{C}$ for 3.5 minutes in a thermal cycler (Perkin-Elmer, Foster City, California). Eight microliters of each amplification reaction was analyzed on ethidium bromide-stained $2 \%$ agarose gels. A single band of approximately 300 base pairs corresponds to a clonal lgH gene rearrangement.

\section{Detection of EBV in SCID Lymphomas}

The presence of EBV in xenotransplanted lymphoid tumors was identified by PCR analysis under standard conditions by means of the following oligonucleotide primers: EBV-1810 sense (Forward (F), 5' CGC AGG GAT GCC TGG ACA CA 3'; 20 mer. EBV-1963 antisense Reverse (R), 5' CTG TTT GTG CTT GTG GC 3'; and 20 mer (Menin et al, 1996). EBV positive and negative Burkitt's lymphoma cell lines (Raji and Ramos, respectively) were used as controls.

\section{Acknowledgements}

We wish to thank Hsiu-Li Su, Janet Craig, Kent Claypool, and Tom Brooks for technical assistance and Susan Hughes for manuscript preparation.

\section{References}

Anonymous (1982). Non-Hodgkin's lymphoma pathologic classification project: National Cancer Institute sponsored study of classifications of non-Hodgkin's lymphomas: Summary and description of a Working Formulation for clinical usage. Cancer 49:2112-2135.

Beran M, Pisa P, Kantarjian H, Porwit A, and Bjorkholm (1994). Growth of sensitive and drug-resistant human myeloid leukemia cells in SCID mice. Hematol Pathol 8:135-154. 
Beran M, Pisa P, O’Brien S, Kurzrock R, Siciliano M, Cork A, Andersson BS, Kohli V, and Kantarjian H (1993). Biological properties and growth in SCID mice of a new myelogenous leukemia cell line (KBM-5) derived from chronic myelogenous leukemia cells in the blastic phase. Cancer Res 53:36033610.

Bosma GC, Custer RP, and Bosma MJ (1983). A severe combined immunodeficiency mutation in the mouse. Nature 301:527-530.

Bosma MJ and Carrol AM (1991). The SCID mouse mutant: Definition, characterization, and potential uses. Annu Rev Immunol 9:323-350.

Butcher EC, Williams M, Youngman K, Rott L, and Briskin M (1999). Lymphocyte trafficking and regional immunity. Adv Immunol 72:209-253.

Cesano A, Hoxie JA, Langem B, Nowell PC, Bishop J, and Santoli D (1992). The severe combined immunodeficient (SCID) mouse as a model for human myeloid leukemias. Oncogene 7:827-836.

Chelstrom LM, Gunther R, Simon J, Raimondi SC, Krance R, Crist WM, and Uckun FM (1994). Childhood acute myeloid leukemia in mice pretreated with radiation and anti-asialo GM1. Anticancer Res 84:20-26.

Custer RP, Bosma GC, and Bosma MJ (1985). Severe combined immunodeficiency (SCID) in the mouse: Pathology, reconstitution, neoplasms. Am J Pathol 120:464-477.

Deane M and Norton JD (1990). Immunoglobulin heavy chain variable region family usage is independent of tumor cell phenotype in human B-lineage leukemias. Eur J Immunol 20:2209-2217.

DeMartini RM, Turner RR, Boone DC, Lukes RJ, and Parker JW (1988). Lymphocyte immunophenotyping of B-cell lymphomas: A flow cytometric analysis of neoplastic and non-neoplastic cells in 271 cases. Clin Immunol Immunopath 49:365-379.

Dorshkind K, Pollack SB, Bosma MJ, and Phillips RA (1985). Natural killer cells are present in mice with severe combined immunodeficiency. J Immunol 134:3798-3801.

Drillenburg P, van der Voort R, Koopman G, Dragosics B, van Krieken JH, Kluin P, Meenan J, Lazarovits Al, Radaszkiewicz T, and Pals ST (1997). Preferential expression of the mucosal homing receptor integrin $\alpha 4 \beta 7$ in gastrointestinal nonHodgkin's lymphomas. Am J Pathol 150:919-927.

Duchosal MA, Eming SA, McConahey PJ, and Dixon FJ (1992). The hu-PBL-SCID mouse model: Long-term human serologic evolution associated with the xenogeneic transfer of human peripheral blood leukocytes into SCID mice. Cell Immunol 139:468-477.

Felsher DW, Rhim SH, and Braun JA (1990). A murine model for B-cell lymphomagenesis in immunocompromised hosts-Natural killer cells are an important component of host resistance to premalignant B-cell lines. Cancer Res 50:7050-7056.

Fidler IJ (1986). Rationale and methods for the use of nude mice to study the biology and therapy of human cancer metastasis. Cancer Metastasis Rev 5:29-49.

Flavell DJ (1996). Modeling human leukemia and lymphoma in severe combined immunodeficient (SCID) mice: Practical applications. Hematol Oncol 14:67-82.
Ford R, Tamayo A, Martin B, Niu K, Claypool K, Cabanillas F, and Ambrus $J$ (1995). Identification of B-Cell growth factors (interleukin-14; high molecular weight-B-cell growth factors) in effusion fluids from patients with aggressive B-cell lymphomas. Blood 86:283-293.

Ford RJ, Bryant J, Claypool K, and Cabanillas F (1996). Human lymphoma models in SCID mice: Non-Hodgkin and Hodgkin's. Blood 88(Suppl 1):386a.

Ford RJ, Luthra R, Bryant J, Tamayo A, and Curiel T (1998). In vitro and in vivo models for mantle cell lymphoma. Blood 92:1288a.

Harris NL, Jaffe ES, Stein H, Bank PM, Chan JKL, Cleary ML, Delsol G, Christin De WP, Falini B, Gatter KC, Grogan TM, Isaacson PG, Knowles DM, Mason DY, Muller-Hermelink HK, Pileri MA, Ralfkiaer E, and Warnke SA (1994). A revised European-American Classification of lymphoid neoplasms: A proposal from the international lymphoma study group. Blood 84:1361-1392.

Herberman RB, Djeu JY, Kay D, Ortaldo JR, Riccardi C, Bonnard GD, Holden HT, Fagnani R, Santoni A, and Puccetti P (1979). Natural killer cells: Characteristics and regulation of activity. Immunol Rev 44:44-70.

Herberman RB, Nunn ME, and Lavrin DH (1975). Natural cytotoxic reactivity of mouse lymphoid cells against syngeneic and allogeneic tumors. I. Distribution of reactivity and specificity. Int J Cancer 16:216-229.

Hesse JE, Lieber MR, and Gellert M (1987). Extrachromosomal DNA substrates in pre-B cells undergo inversion or deletion at immunoglobulin V-(D)-J joining signals. Cell 49: $1-9$.

Isaacson PG (1999a). Gastric MALT Iymphoma: From concept to cure. Ann Oncol 10:637-645.

Isaacson PG (1999b). Gastrointestinal lymphomas of T- and B- cell types. Mod Pathol 12:151-158.

Kamel-Reid S, and Dick JE (1988). Engraftment of immunedeficient mice with human hematopoietic stem cells. Science 242:1706-1709.

Kiessling R, Klein E, and Wigzell H (1975). Natural killer cells in the mouse. I. Cytotoxic cells with specificity for mouse Moloney leukemia cells. Specificity and distribution according to genotype. Eur J Immunol 5:112-117.

Kiessling $\mathrm{R}$ and Wigzell $\mathrm{H}$ (1979). An analysis of the murine NK cell as to structure, function and biological relevance. Immunol Rev 44:166-208.

Kroon JFED, Kluin PM, Nelemans HC, Willemze R, and Falkenburg JHF (1994). Homing and antigenic characterization of a human Non-Hodgkin's lymphoma B cell line in severe combined immunodeficient (SCID) mice. Leukemia 8:1385-1391.

Lauzon RJ, Siminovitch KA, Fulop GM, Phillips RA, and Roder JC (1986). An expanded population of natural killer cells in mice severe combined immunodeficiency (SCID) lack rearrangement and expression of $\mathrm{T}$ cell receptor genes. $\mathrm{J}$ Exp Med 164:1797-1801.

Lehmann MT, Saxon A, and Lehmann PV (1995). The human immune system in hu-PBL-SCID mice. Immunol Today 16: $529-533$. 
Lieber MR, Hesse JE, and Lewis S (1988). The defect in murine severe combined immune deficiency. Joining of signal sequences but not coding segments in $V(D) J$ recombination. Cell 55:7-16.

Malynn B, Blackwell TK, and Fulop G (1988). The SCID affects the final step of the immunoglobulin VDJ recombinase mechanism. Cell 54:453-460.

Martino G, Anastasi J, Feng J, Mcshan C, DeGroot L, Quintans J, and Grimaldi LME (1993). The fate of human peripheral blood lymphocytes after transplantation into SCID mice. Eur J Immunol 23:1023-1028.

Menin C, Ometto L, Verones A, Roncella S, Corneo B, Montagna M, Coppola V, Veronese ML, Indraccolo S, Amadori A, De Rossi A, Ferrarini M, Chieco-Bianchi L, and D'Andrea E (1996). Analysis of Epstein-Barr Virus (EBV) type and variant in spontaneous lymphoblastoid cells and HuSCID mouse tumors. Mol and Cellul Probes 10:453-461.

Mosier DE, Gulizia RJ, Baird SM, and Wilson DB (1988). Transfer of a functional human immune system to mice with severe combined immunodeficiency. Nature 335:256-259.

Mosier DE, Picchio GR, Baird SM, Kobayashi R, and Kipps TJ (1992). Epstein-Barr virus-induced human B-cell lymphomas in SCID mice reconstituted with human peripheral blood leukocytes. Cancer Res 52:5552s-5553s.

Motokura T, Bloom T, Kim HG, Juppner H, Ruderman JV, Kronenberg HM, and Arnold A (1991). A novel cyclin encoded by a bcl-1 linked candidate oncogene. Nature 50:512-515.

Moynihan MJ, Bast MA, Chan WC, Delabie J, Wickert RS, Wu G, and Weisenburger DD (1996). Lymphomatous polyposis: A neoplasm of either follicular mantle or germinal center cell origin. Am J Surg Pathol 20:442-452.
Namikawa R, Ueda R, and Kyoizumi S (1993). Growth of human myeloid leukemias in the human marrow environment of SCID-hu mice. Blood 82:2526-2536.

Picker LJ, Medeiros LJ, Weiss LM, Warnke RA, and Butcher EC (1988). Expression of lymphocyte homing receptor antigen in non-Hodgkin's lymphoma. Am J Pathol 30:496-504.

Rosenberg CL, Wong E, Petty EM, Bale AE, Tsujimoto Y, Harris NL, and Arnold A (1991). Prad1, a candidate BCL1 oncogene: Mapping and expression in centrocytic lymphoma. Proc Natl Acad Sci USA 88:9638-9642.

Sandhu J, Shpitz B, Gallinger S, and Hozumi N (1994). Human primary immune response in SCID mice engrafted with human peripheral blood lymphocytes. J Immunol 152: 3806-3813.

Sawyers CL, Gishizky ML, Quan S, Golde DW, and Witte ON (1992). Propagation of human blastic myeloid leukemias in the SCID mouse. Blood 79:2089-2098.

Sundaresan A, Claypool K, Mehta K, Lopez-Berestein G, Cabanillas F, and Ford RJ Jr (1997). Retinoid-mediated inhibition of cell growth with stimulation of apoptosis in aggressive B-cell lymphomas. Cell Growth Differ 8:10711082.

Waller EK, Kamel OW, Cleary ML, Maumdar AS, Schick MR, Lieberman M, and Weissman IL (1991). Growth of primary T-cell non-Hodgkin's lymphomata in SCID-hu mice: Requirement for a human lymphoid microenvironment. Blood 78 : 2650-2665.

Zukerberg LR, Yang W-I, Arnold A, and Harris NL (1995). Cyclin D1 expression in non-Hodgkin's lymphomas. Am J Clin Pathol 103:756-760. 